Dextropropoxyphene was dispensed with alprazolam on 261 occasions (this combination may increase the central depressant effects of alprazolam) and with carbamazepine on 240 (this combination may cause serious toxic effects by increasing plasma concentrations of carbamazepine). Cisapride was dispensed with erythromycin on five occasions, with clarithromycin on three, fluconazole on 24, and itraconazole on one; any of these combinations may result in torsades de pointes, syncope, cardiac arrest, and sudden death.

\section{Comment}

Although the percentage of potential drug interactions that may have serious clinical consequences (type D) was low (1.4\%), serious and potentially fatal drug interactions-for example, NSAID and warfarin, potassium supplements and potassium sparing diuretics, dextropropoxyphene and carbamazepine, and cisapride and fluconazole-were detected. The risk of interactions with cisapride was known in $1996,{ }^{5}$ and cisapride, which is still available in Sweden, is being withdrawn in many countries.

Prescribing pairs of drugs with potential interactions increases the risk of, but need not lead to, an adverse reaction. Many drug interactions are susceptible to control by dose adjustment; moreover, some are beneficial and are exploited in therapeutics.

National monitoring of potential drug interactions in Sweden is feasible. Differences in healthcare systems need to be considered when extrapolating the results of this study to other countries.
Presented in part at the International Society of Pharmacoepidemiology annual meeting in Barcelona, Spain, 19-23 August 2000. We are grateful to the Swedish Centre for Epidemiology (National Board of Health and Welfare) and the National Corporation of Swedish Pharmacies (Apoteket AB, formerly Apotekesbolaget) for access to the Swedish Health Care Database on Pharmaceutical Agents, and to Frank Wollheim, Department of Rheumatology, Lund University Hospital for his support.

Contributors: JM had the original idea for the article, designed and performed the analysis and interpretation of the data, and drafted, wrote, and revised the content. JF programmed the database. All authors were involved in the study design, data interpretation, content revision, and approval of the final version.JM is the guarantor of the paper.

Funding: Nätverk för Läkemedelsepidemiologi (NEPI) foundation; Government grant (JM) from Avtal om Läkarutbildning och Forskning (founding document number M : E 39 390/98).

Competing interests: None declared.

1 Stockley IH. Drug interactions: a source book of adverse interactions, their mechanisms, clinical importance and management. London: Pharmaceutical Press, 1996.

2 Rasbash J, Browne W, Goldstein H, Yang M, Plewis I, Healy M, et al. A user's guide to MLwiN. London: Institute of Education, University of London, 1999.

3 Sjöqvist F. Drug interactions. In: The Swedish Drug Compendium "FASS" Läkemedel $i$ Sverige. Förtecking över humanläkemedel. Stockholm: LINFO Läkemedelsinformation AB, 1999:1383-1453.

4 Sjöqvist F. Drug interactions. In: The Swedish Drug Compendium "FASS". Läkemedel $i$ Sverige. Förtecking över humanläkemedel. Stockholm: LINFO Läkemedelsinformation AB, 2000:1481-1556.

5 Biverkningsinformation: Prepulsid (cisaprid) - hjärtarytmi: Påminnelse. Information från Läkemedelsverket 1996;7(6):27.

(Accepted 29 March 2001)

\title{
Rationing in the NHS: audit of outcome and acceptance of restriction criteria for minor operations
}

\author{
Ciaran P O’Boyle, Richard P Cole
}

Odstock Centre for Burns, Plastic and Maxillofacial Surgery, Salisbury District Hospital, Salisbury SP2 8B] Ciaran P O'Boyle research fellow Richard P Cole consultant plastic surgeon

Correspondence to:

C P O'Boyle ciaranoboyle@ saintly.com

BMJ 2001;323:428-9
General practitioners' referrals for skin lesion excisions constitute a large proportion of cases seen at plastic surgery clinics. Escalating rates of skin cancer have increased the numbers of urgent referrals due to suspicious looking skin lesions. As a result, patients with clinically benign lesions spend long periods on waiting lists, exceeding the waiting times agreed in negotiated contracts.

In March 1999, a total of 666 patients had been waiting over one year for minor plastic surgery at Salisbury District Hospital. In response, Salisbury Health Care NHS Trust and Wiltshire Health Authority proposed a new system of contract exclusions, whereby only patients with lesions that suggested malignancy or that were disfiguring or potentially disfiguring would be seen. The health authority and the trust assumed that excluded patients would not be seen or treated elsewhere. The consultant plastic surgeons reviewed the referral letters for patients who were not given an operation and returned the letters with explanatory notes.

This study aimed to assess the acceptability of the new system among patients and general practitioners and to determine the outcome of cases excluded under the new criteria.

\section{Methods and results}

Details of all referrals rejected under the new system were collected for six months after its inception on 1 September 1999. In each case, the site and description of the lesion were recorded. General practitioners and patients were contacted by telephone to assess their satisfaction with the system and to determine whether further referrals for excision had been made. The histological diagnosis was obtained for lesions excised after re-referral.

In six months, 112 referrals were rejected. Of these, 99 contactable patients (134 lesions) were followed up; 103 lesions (77\%) were in the head and neck. In many referral letters the clinical description was non-specific but did not suggest malignancy or disfigurement.

Nineteen $(19 \%)$ patients later had their lesions excised; 18 patients had benign pathology, and one had a squamous cell carcinoma. The patient with the carcinoma had been refused treatment solely on the basis of a referral letter-on grounds that this was a cosmetic problem-and afterwards sought a private consultation and subsequent excision. 
Most patients (77\%) and general practitioners $(63 \%)$ were dissatisfied with the new contract exclusion criteria; $23 \%$ of patients and $36 \%$ of general practitioners were satisfied with it. In all, $51 \%$ of general practitioners re-referred their patient either to another hospital $(36 \%)$ or back to the original unit $(15 \%)$.

\section{Comment}

There is low acceptance among general practitioners and patients of recently imposed contract exclusions. Subsequent re-referrals transfer patients from one waiting list to another, wasting NHS resources without making waiting lists shorter. It is worrying that one patient with a malignancy was refused NHS treatment under the new system, and this error is consistent with the findings of previous research suggesting that it is unreasonable to expect general practitioners to have the diagnostic and therapeutic skills of specialist clinicians. ${ }^{1}$ These findings raise questions about the general practitioner's role in diagnosis and management in the context of restricted secondary services.

Rationing of health services is emotive, involving issues of ethics, finance, and standards of care. ${ }^{23}$ Although possibly a legitimate factor in modern healthcare provision, rationing may be unacceptably restrictive to patients and clinicians. In Florida in 1996, Medicare's decision to restrict funding of excision of actinic keratoses resulted in litigation (although unsuccessful) by the American Academy of Dermatology, the Florida Society of Dermatology, and the Seniors Coalition. ${ }^{4}$

With rising political and financial pressures to cut NHS waiting lists, patients with urgent problems are given priority. Those with apparently benign conditions may wait for years to be seen in clinics, or they could be excluded from waiting lists altogether. ${ }^{5}$ If similar restrictions on service provision continue, this could constitute implicit acknowledgement of an "acceptable level" of missed malignancy. Although rationing of services may be necessary, care must be exercised in its application.

Contributors: CO'B conducted the study and collated the data The paper was written jointly by $\mathrm{CO}^{\prime} \mathrm{B}$ and $\mathrm{RC}$. RC is the guarantor.

Funding: Plastic surgery department, Salisbury Health Care NHS Trust.

Competing interests: None declared.

1 McWilliams LJ, Knox F, Wilkinson N, Oogarah P. Performance of skin biopsies by general practitioners. BMJ 1991;303:1177-9.

Latham SR. The ethics of managed care: financial incentives to limit care. Clin Plast Surg 1999;2:115-21.

3 Asch DA, Ubel PA. Rationing by any other name. $N$ Engl $J$ Med 1997;336:1668-71.

4 Charatan FB. Skin lesion removal rationed in Florida. BMJ 1996;313 1506

5 Timmons TJ. Rationing of surgery in the National Health Service: the plastic surgery model. Ann R Coll Surg Engl 2000;82(suppl):332-3.

(Accepted 10 April 2001)

\title{
Cohort survey of heart valve replacement patients: does the valve card scheme have room for improvement?
}

\author{
Maria-Benedicta Edwards, Kenneth M Taylor
}

Patients undergoing heart valve replacement have a high risk of experiencing valve related adverse events such as acute failure of the valve mechanism, valve thrombosis, and peripheral emboli. Immediate availability of information about valves for any valve patient presenting at outpatient clinics, general practitioner surgeries, or acutely at accident and emergency departments may lead to early suspicion and diagnosis of specific complications known to be associated with particular heart valves. ${ }^{1-3}$ Postoperative surveillance is therefore crucial.

Valve manufacturers have established schemes to provide patients with cards that give details of the valve prosthesis. The process has four to five steps and can fail at any stage, for example when the implanting centre sends implant details to the valve manufacturer (usually via the UK distributor), or when the valve manufacturer sends the implant card to the patient via the implanting centre.

Clinicians have been concerned that current distribution systems may be less than optimal; although valve card schemes have been in place for many years, they have not been independently evaluated. We surveyed a cohort of UK patients who had had heart valves replaced to determine what proportion received an implant card, and when they received it relative to their implant date.

\section{Methods and results}

The UK heart valve registry prospectively collects data on all valve replacements carried out in the United Kingdom. ${ }^{4}$ Currently $>79000$ patients and $>88000$ heart valves are registered. Patients who underwent heart valve replacement between 1 January 1998 and 31 December 1998 were identified from the database and checked against national registers (England, Scotland, Wales, and Northern Ireland) for deceased patients and those lost to follow up. The 2582 patients identified were sent an anonymised questionnaire and asked the date of their operation, if they had received an implant card, and the interval between operation and card receipt.

A total of 1914 patients (74\%) responded to the questionnaire. Of these, 47\% $(n=898)$ had not received an implant card 12 months postoperatively (figure). In all, 14\% had received their implant card one month postoperatively, $30 \%$ three months postoperatively, and $43 \%$ six months postoperatively. A small number of patients $(\leqslant 1 \%)$ could not remember how long after surgery the card had arrived. $45 \%$ identified themselves and were matched against valve manufacturer and implanting centre; $60 \%$ of these $(n=519)$ did not receive an implant card. Three of nine valve manufacturers achieved $>50 \%$ (range $53-71 \%$ ) success in getting implant cards to patients within a year post-
United Kingdom Heart Valve

Registry,

Department of Cardiothoracic Surgery,

Hammersmith

Hospital, London W12 0NN

Maria-Benedicta

Edwards

manager

Kenneth M Taylor professor

Correspondence to: M-B Edwards m.b.edwards@ic. ac.uk

BMJ 2001;323:429-30

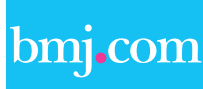

A list of participating hospitals is available on the $B M J$ 's website 